\title{
“Pyknodysostosis" A Case Report
}

\author{
Sapkota KK ${ }^{1}$, Gupta $V^{2}$, Shrivastav $\mathbf{C P}^{3}$ \\ ${ }^{1}$ Dr. Karna K Sapkota, Lecturer, ${ }^{2}$ Prof. Veena Gupta, Professor and Head of Department, ${ }^{3}$ Dr. CP Shrivastav, Associate \\ Professor, Department of Paediatrics, Nepalgunj Medical College, Kohalpur, Nepalgunj, Nepal.
}

Address for Correspondence: Dr. Karna K Sapkota, E-mail: karnasapkota@yahoo.com

\begin{abstract}
Pyknodysostosis is a rare disorder of skeletal dysplasia that is inherited as an autosomal recessive genetic trait. Several mutations have been found in the gene encoding cathepsin $\mathrm{K}$ - a lysosomal cysteine protease and the gene situated at 1q21. A mutation in this gene leads to loss of enzyme for osteoclastic activities responsible for the metabolism of skeletal system leading to defective bone remodeling and resorption and various other skeletal abnormalities. Here we report a case of 12 year old female from mid-western hilly region of Nepal with Pyknodysostosis having fracture femur and other skeletal dysplasia.
\end{abstract}

The characteristic features of this syndrome are dwarfism, large open fontenelles, wide cranial sutures, small retrograde mandible, multiple fractures and osteosclerosis, dental abnormalities, short and broad hands and feet, blue sclera, multiple fractures and nail may be dysplastic ${ }^{1}$.

Key words: Pyknodysostosis, dysplasia, short stature

\section{Case Report}

12-year-old girl, born to consanguineous marriage, Awas referred to the orthopedic department for fracture of femur and to the department of paediatrics by orthopedic surgeon with the symptoms and signs of short stature, wide open sutures and fontenelles characteristic facies and history of recurrent fractures following trivial injuries. On taking the complete history; she was born at term by normal vaginal delivery at home without any perinatal complications and her developmental milestones were normal as per her age and a normal IQ at present. She has one younger brother who does not have any problems and is normal but her younger sister who is 7 years of age has similar features as stated by her mother. He however could not be examined due to difficulty in bringing him due to transportation problems.Upon examination, her height was $107 \mathrm{~cm}$ (below the $10^{\text {th }}$ percentile for her age), weight $19 \mathrm{~kg}$, head circumference $51 \mathrm{cms}$ and she had an upper and lower segment ratio of 1.2: 1.0. The dolicocephalic head had mild frontal bossing and all the cranial sutures were open along with a wide and open boggy anterior and posterior fontenelles. She had a small face with beaked nose and proptosis (Fig: 4). A retrognathic mandible with history of significant delay in the primary (at 15 months) and secondary dentition.
She had a narrow high-arched palate. Her teeth were pigmented and malformed. She had small hands with dystrophic terminal phalanges showing koilonychia on all the nails of both her hands (Fig: 5) and feet. Even though her chest showed pectus carinatum; she had a good expansion and she did not have any clinically detectable abnormalities of the heart. The abdominal examination revealed a spleen that was just palpable and a liver span of $11.5 \mathrm{~cm}$. Skeletal examination revealed a fracture of the left shaft of femur and a deformed right thigh. The other general examination and examination of the other systems were unremarkable.

X-ray of long bones showed a generalized increase in bone density, fracture of left shaft of femur and deformed right femur due to an old healed fracture (Fig: 1). The X-ray of the skull showed widened sutures, large and open anterior and posterior fontenelles and a blurring of mandibular angle along with sclerotic bone (Fig: 2). X-ray of the hands and wrists showed resorption of the terminal phalanges (Fig: 3). Blood tests reports were as follows; Hb-11.9gm\%, TLC-8600/ cu mm (N-57\%, L-41\%, E-02\%), Blood sugar ${ }^{-9}-98$ mg/ dl, Serum Creatinine- $0.4 \mathrm{mg} / \mathrm{dl}$, Alkaline Phosphatase167 I.U/L, Serum Calcium-9.3 mg/dl. 


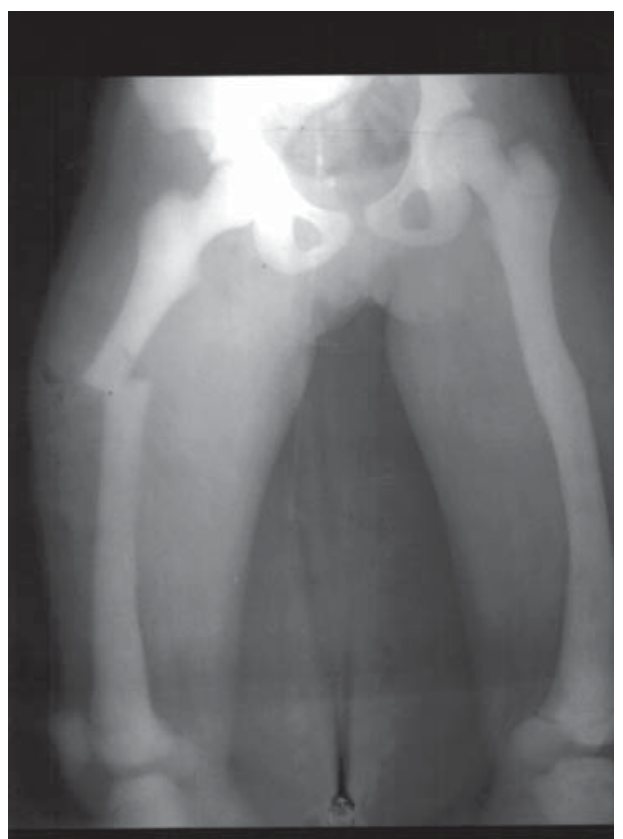

Fig 1: X-ray Showing Fracture of the Right Femur.

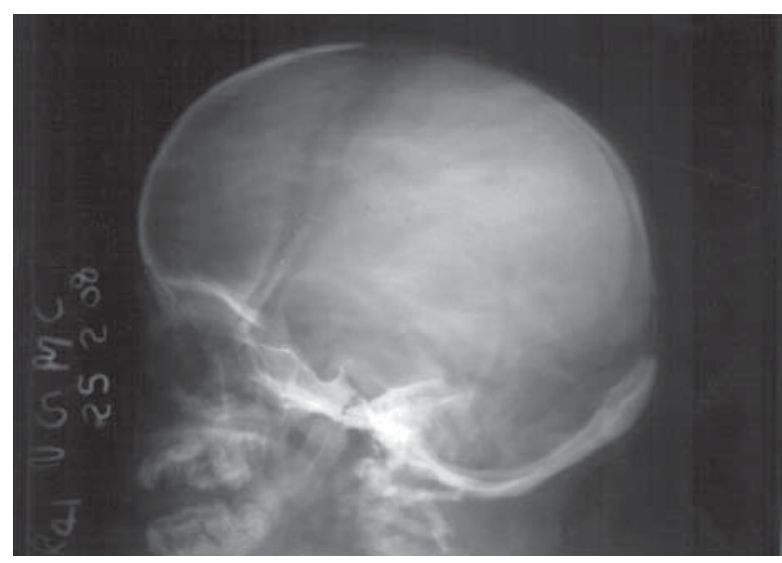

Fig 2: Showing X-ray of the Skull which shows widened sutures, large and open anterior and posterior fontenelles and a blurring of mandibular angle along with sclerotic bone.

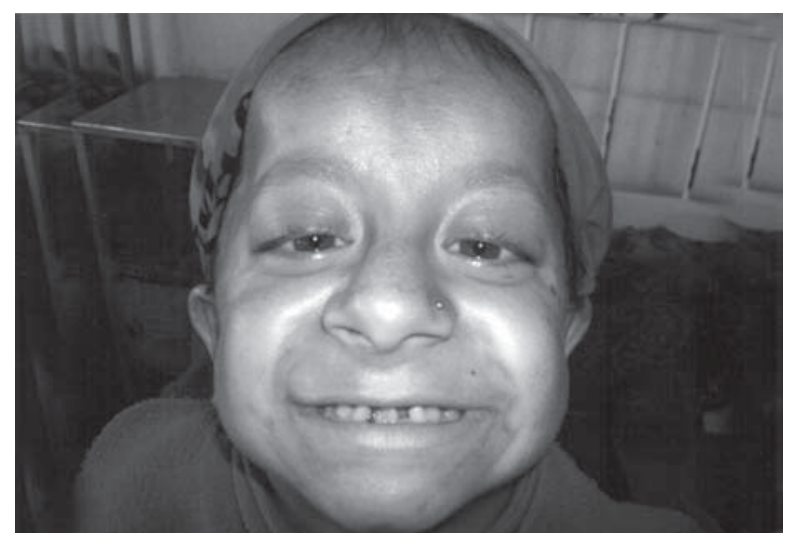

Fig 4: Showing a small face with beaked nose and proptosis.

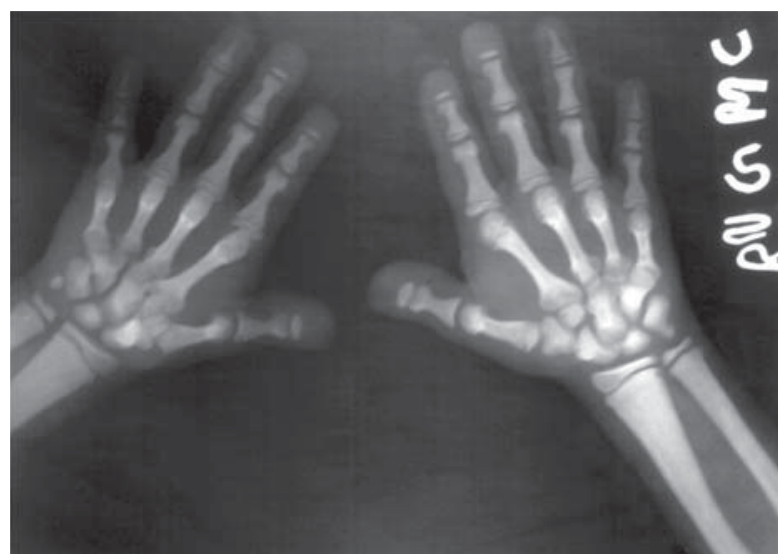

Fig 3: Showing X-ray of the hands and wrists which shows resorption of the terminal phalanges.

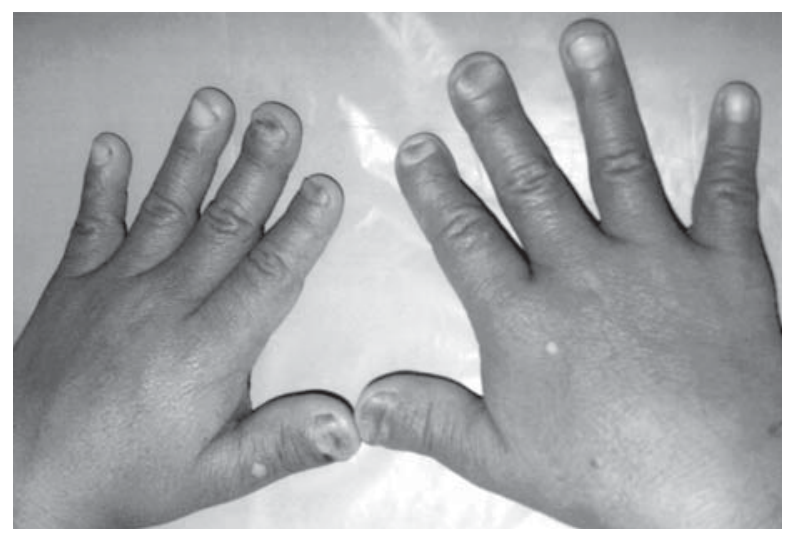

Fig 5: Showing small hands with dystrophic terminal phalanges having koilonychia on all the nails of both her hands. 


\section{Discussion}

"Pycnos" meaning thick or dense, a Greek word, from where the name Pyknodysostosis has been derived $^{2}$. The condition was independently described by Maroteaux ${ }^{3}$ and Lamy and by Andren et al ${ }^{4}$ in 1962. Latest clinical brief with a case report was published by Singh Arvind Rup and associates in $2004^{5}$. The disease shows high consanguinity ( $30 \%$ to $80 \%$ ) among parents of the patient and has an equal sex distribution ${ }^{6}$. It is characterized by proportionate short height, osteosclerosis, wormian bones of skull, lateral dysplasia of clavicles, loss of mandibular angle, dystrophic distal phalanges of hands and feet, fractures and tooth deformities ${ }^{3,6}$. The clavicles may be hypoplastic or absent. The long bones may be thin and tubular with increased density ${ }^{2}$. They may have koilonychias, blue sclera and have wide open fontenelles and sutures ${ }^{1}$.

Our case had normal clavicles and had no anemia but showed all the other characteristic features. Hepatosplenomegaly suggest the possibility of extra medullary erythropoesis in Pyknodysostosis. Some patients have history of repeated chest infections and sleep apnea due to upper respiratory obstruction? ${ }^{7}$. The intellectual and sexual development is usually normal in these patients ${ }^{7}$ as was in our patient. Soliman and co-workers in $1992^{8}$ reported low insulin-like growth factor-1 (IGF1) concentration in 5 out of 6 patients with the disorder and noted an increase in the linear growth and the level of IGF1 with replacement of growth hormone (GH). Pyknodysostosis, by ultra structural studies have shown that the osteoclasts function normally in demineralizing bone but do not adequately degrade the organic matrix ${ }^{9}$. In these patients, the serum and urine levels of NTX and CTX markers that detect N and $\mathrm{C}$ termini in telopeptide cross-links in collagen type I are low, showing defective degradation of collagen type I which constitutes $95 \%$ of the bone matrix ${ }^{10}$. Till date 14 mutations have been identified in the CTSK gene, 12 being missense/nonsense, 1 splicing and 1 small deletion ${ }^{11}$. The molecular analysis of our case has not been conducted due to lack of facilities. Pyknodysostosis is compatible with a normal life span. The tendency of spontaneous fractures decreases with age, therefore the family should be counselled and reassured about the good prognosis ${ }^{5}$.

Acknowledgement: None

Funding: None

Conflict of Interest: None

\section{References}

1. William A. Horton, Jacqueline T. Hecht. The skeletal Dysplasias: Pyknodysostosis: Nelson Text Book of Pediatrics $16^{\text {th }}$ ed: $2125-2126$.

2. Edelson JG, Obad S, Geiger R, On A, Artul HJ. Pyknodysostosis: Orthopedic Aspects with Description of 14 New Cases. Clin Orthop 1992; 280: 263-276.

3. Maroteaux P, Lamy M. La Pycnodystose. Presse Med 1962; 70: 999-1002.

4. Andren L, Dymling JF, Hogeman KE, Wendeberg B. Osteopetrosis Acro-Osteolytica: A Syndrome of Osteoporosis, Acro-Osteolysis and Open Sutures of Skull. Acta Chir Scand 1962; 124: 496-507.

5. Singh AR, Kaur A, Anand N K, Singh JR. Pyknodysostosis: Visceral Manifestations and Simian Crease: Clinical Brief: Indian $J$ Pediatr May; 71 (5); 453-5.

6. Sedano HP, Gorlin RJ, Anderson VE. Pycnodysostosis: Clinical and Genetic Considerations. Am J Dis Child 1968; 116: 70-77.

7. deAgustin JC, Jover P, Leon M, Oliver A, Izal E, Utrilla JG. Pyknodysostosis: Extreme Cause of' Sleep Apnea. Cir Pediatr 1992; 5: 105-108.

8. Soliman AT, Rajab A, Al Salmi I, Darwish A, Asfour M. Defective Growth Hormone Secretion in Children with Pycnodysostosis and Improved Linear Growth after Growth Hormone Treatment. Arch Dis Child 1996; 75: 242-244.

9. Gelb BD, Spencer E, Obad S, Edelson JG, Faure S, Weissenbach, Desnick RJ. Pycnodysostosis: Refined Linkage and Radiation Hybrid Analyses Reduce the Critical Region to $2 \mathrm{cM}$ at 1q21 and Map Two Candidate Genes. Hum Genet 1996; 98 : 141-144.

10. Nishi Y, Atley L, Eyre DE, Edelson JG, SupertiFurga A, Yasuda T et al. Determination of Bone Markers in Pycnodysostosis: Effects of Cathepsin K Deficiency on Bone Matrix Degradation. J Bone Miner Res 1999; 14: 1902-1908.

11. Stenson PD, Ball EV, Mort M, Phillips AD, Shiel JA, Thomas NS et al. Human Gene Mutation Database (HGMD): 2003 update. Hum Mutat 2003; 21: 577-581. 